\title{
О.А. Новиков
}

\section{ФОРМИРОВАНИЕ И ОЦЕНКА РЕКЛАМНО-ИНФОРМАЦИОННОГО ПРОСТРАНСТВА РИТЕЙЛА}

В статье рассмотрена категория «рекламно-информационное пространство» в формате новой системы взаимоотношений между субъектами территории. Проводится структурный анализ, выявляются тенденции, направления теории и практики применения формирования рекламноинформационного пространства ритейла в маркетинге территории. Предлагается авторская методология оценки рекламно-информационного пространства ритейла, а также оценка эффективности мерчандайзинга.

Ключевые слова: маркетинг территории, модель рекламно-информационного пространства, конкурентоспособность территории, имидж, оценка эффективности, показатели мерчандайзинга, POS-материалы, структурно-функциональный анализ рекламно-информационного пространства.

В последнее время в бизнесе субъектов территории наметилась тенденция увеличения роли рекламно-информационного пространства ритейла. Обеспечение эффективности маркетинга территории непосредственно связано с формированием рекламно-информационного пространства ритейла, которое создает уникальные свойства маркетинга территории как товара, приносит выгоду и пользу сообществу людей, проживающих на территории, производителям товаров и услуг.

Формирование рекламно-информационного пространства ритейла. Процесс формирования рекламно-информационного пространства ритейла включает в себя разработку материалов, которые передают сообщение о продажах в том месте, где потребитель готов сделать покупку.

По поводу терминологии такой автор, как А.А. Воат представляет рекламно-информационное пространство как «один из системообразующих элементов общества, объединяющий в себе все рекламно-информационные ресурсы и рекламную инфраструктуру, т. е. всю сферу использования, распространения и формирования

(C) Новиков О.А., 2016 
рекламной информации, включая различные рекламно-информационные сообщения и технологии их сопровождения» ${ }^{1}$.

Ф.Г. Панкратов в понятие «рекламно-информационное пространство предприятий розничной торговли» включает совокупность видов и средств рекламы, применяемых в местах продажи товаров, в создании экстерьера магазина, приемов и методов продвижения товаров, ориентированных на стимулирование продаж и формирование индивидуального имиджа торгового предприятия ${ }^{2}$.

Формирование рекламно-информационного пространства ритейла - это надежный инструмент для увеличения продаж на территории региона. «Рекламно-информационное пространство - не просто инструмент маркетинга, а специфическая информация, которая производит определенное воздействие на массовое сознание» ${ }^{3}$.

Основными целями формирования рекламно-информационного пространства ритейла, на наш взгляд, являются: рост его оборота, престижа, создание конкурентного преимущества и имиджа, закрепление в сознании покупателя устойчивого положительного бренда товара, управление покупательским поведением и покупательскими потоками.

К основным элементам рекламно-информационного пространства ритейла следует отнести: экстерьер и интерьер магазина; POS-материалы; зонирование торгового зала; инструменты мерчандайзинга.

Экстерьер и интерьер магазина. Окружающая территория, оформление входа и витрин, фасада, площадь магазина, парковка это первые элементы имиджа, которые требуют детальной проработки. Экстерьер должен соответствовать философии бизнеса и имиджу магазина. От дизайна интерьера магазина зависит формирование лояльности покупателя, построение эффективных коммуникаций с ним, рост покупательской активности. Интерьер магазина должен включать элементы фирменного стиля, целью которого является формирование имиджа, узнаваемости бренда, убеждение и стимулирование продаж, привлечение к субъекту ритейла покупателей разных территорий.

$P O S$-материаль. В практике управления покупательским поведением в маркетинге территории целесообразно применять POS materials - средства оформления мест продаж, т. е. эффективный инструмент коммуникаций, брендинга, мотивации потребителя в пяти функциональных зонах ритейла:

1) функция наружного оформления - локализация места продажи. К средствам наружного оформления относятся: комплексное оформление фасада, оформление витрин, выносные конструкции, 
торцевые брандмауэры, панель-кронштейны, крышные установки, тротуарная графика и др.;

2) функция входной группы - напомнить покупателю о бренде, мотивировать его к покупке. К средствам входной группы относятся: таблички «открыто/закрыто», таблички с режимом работы, таблички-стикеры «от себя/на себя», рекламные стикеры, напольные стикеры непосредственно перед или за входной дверью;

3) функция POS-материалов в торговом зале - напомнить покупателю о товаре и направить его к месту выкладки товара. Элементы POS-материалов в торговом зале: напольная графика, воблеры, стикеры, световые короба, мобайлы и джумби, световые панно, электронные информационные киоски, гирлянды и др.;

4) функция POS-материалов в местах выкладки - инициировать у покупателя желание приобрести товар у конкретного территориального ритейла. POS-материалы в местах выкладки: шелфтокеры и шелфорганайзеры, ценники с логотипом, воблеры, шелфстоперы, дисплеи, стойки;

5) функция POS-материалов в прикассовой зоне - экспонирование и привлечение внимания к товарам «импульсивной покупки». POS-материалы в прикассовой зоне: диспенсеры, воблеры, стикеры, лотки для мелочи и световые короба.

Зонирование торгового зала. Ритейл должен постоянно направлять свои усилия на создание позитивной атмосферы торгового зала за счет применения различных видов технологических планировок и торгово-технологического оборудования, оптимального использования площади торгового зала, эффективного размещения товарных групп, управления покупательскими потоками. Организация продажи в торговом зале воздействует одновременно на приверженность и лояльность покупателя к магазину, т. е. для формирования потенциальных покупателей внутри территории.

Инструменты мерчандайзинга. На привлечение внимания потенциальных покупателей к магазину большое влияние оказывают также свет, цвет, музыка, аромамаркетинг, размещение торгово-технологического оборудования, выкладка товара и др. Они предназначены для привлечения внимания покупателей к территориальному ритейлу и повышения рентабельности их продаж.

Сегодня в ритейле успешно можно реализовать товар только с использованием в торговом зале рекламных элементов, не требующих больших затрат, в том числе:

- использование только надписи на полке с названием рекламируемого товара в среднем увеличивает объемы продаж в 1,94 раза;

- специальная выкладка рекламируемого товара в совокупности (реклама товара + яркая надпись с названием товара на месте его 
выкладки + специальная выкладка) приводит к увеличению продаж в 6,29 раза;

- принципы совместного размещения дополняющих продуктов, а также реализация «одного применения товаров» (мясо/птица с товарами для их приготовления - микроволновыми печами) обеспечивает скачок продаж на 70\%;

- наличие рекламного лозунга в среднем увеличивает объемы продаж на $12 \%$.

Таким образом, использование надписей на полках торговой мебели, рациональная выкладка и размещение товаров являются простым и эффективным средством активизации продажи товаров в ритейле. Среди способов продвижения товаров в ритейле ведущее место занимает содержание надписи на полке оборудования:

- название товара - на 24\%;

- полная информация о товаре - на $33 \%$;

- сообщение о размере скидки - на 23\%;

- рекламные лозунги - на 5\%.

Факторы, влияющие на выбор места продаж и стимулирующие покупки товаров: качество товара - $16 \%$; цена - 16\%; удобство расположения магазина - $16 \%$; реклама $-6 \%$; атмосфера $-8 \%$; репутация магазина $-9 \%$; сервис - $4 \%$; услуги $-2 \%$; стимулирование покупок - 4\%; другие факторы - 19\%.

Формирование рекламно-информационного пространства в ритейле является одним из наиболее эффективных инструментов активного влияния на продажи. Следует отметить, что «эффективность» - категория комплексная и может быть оценена лишь на основе системы показателей. Оценка эффективности результатов предполагает необходимость выбора показателей, наиболее полно характеризующие ресурсы, затраты на рекламу и продвижение продаж.

Рекламно-информационное пространство ритейла целесообразно оценивать с точки зрения интерактивного подхода, учитывающего интегрированную долю товара в обороте, демонстрационной площади магазина и прибыли.

Интегральный показатель товарной группь в обороте, площади, прибыли магазина:

$$
U_{m}=\sum_{u=1}^{n} O \times T \times \Pi
$$

где $u=1 \ldots \mathrm{n}-$ количество торговых отделов в магазине;

$O$ - доля товарной группы в обороте магазина;

$T$ - доля товарной группы в демонстрационной площади магазина; $\Pi$ - доля товарной группы в прибыли магазина. 
Интегральный показатель эффективности использования пространства торгового зала магазина:

$$
U_{n}=\sum_{u=1}^{n} K_{o} \times K_{n}
$$

где $u=1 \ldots \mathrm{n}$ - количество торговых отделов в магазине;

$K_{o}-$ коэффициент использования пространства торгового зала

$$
K_{o}=\frac{\text { доля товарной группьь вобороте магазина }}{\text { демонстрационная площадь товарной группы }} ;
$$

$K_{n}$ - коэффициент эффективности использования пространства торгового зала по прибыли

$$
K_{n}=\frac{\text { доля товарной группь в прибыли магазина }}{\text { демонстрационная площадь товарной группь }} .
$$

Эффективность рекламно-информационного пространства можно также определять исходя из прибыли относительно рентабельности демонстрационной площади (РД), рентабельности запаса (PЗ), рентабельности товара $(P T)$ :

$$
\text { РД }=\frac{\Pi}{Д},
$$

где $\Pi$ - торговая прибыль; Д - демонстрационная площадь;

$$
P 3=\frac{\Pi}{3},
$$

где 3 - сумма товарных запасов;

$$
P O=\frac{\Pi}{O},
$$

где $O$ - оборот магазина.

Кроме того, применяются такие экономические показатели, как товарооборот на 1 работника магазина, товарооборот на 1 кв. метр площади торгового зала, сумма среднего чека, а также количество чеков, отражающих число товаров, приобретенных покупателем в магазине. Оборот отражает социально-экономический эффект, характеризуемый объемом удовлетворенных потребностей покупателя, т. е. ту его часть, которая предназначена для покрытия текущих затрат и образования прибыли. Методология оценки проводится как для всего ассортимента товаров, так и для товарных групп и подгрупп, а также для торговых марок при их реализации в брендированных магазинах. 
Применение рассмотренных инструментов формирования рекламно-информационного пространства в ритейле позволяет повысить эффективность хозяйственной деятельности ее субъектов. При этом новые рекламные технологии (мобильные и динамичные POS-конструкции, информационные экраны, мультимедийные терминалы, «говорящие» ценники, магазинное телевидение) позволяют изменять потребности и желания покупателей, отслеживать их перемещение по территории региона, оценивать реакцию на средства мерчандайзинга и рекламных коммуникаций в месте совершения покупки.

Примечания

${ }^{1}$ Boат A.A. Рекламно-информационное пространство и его влияние на формирование массового сознания: социально-философский анализ: Автореф. дис. ... канд. филос. наук. Ярославль, 2011. С. 8.

${ }^{2}$ Панкратов Ф.Г., Баженов Ю.К., Шахурин В.Г. Рекламная деятельность. М.: Дашков и $\mathrm{K}^{\mathrm{o}}, 2007$. С. 81.

${ }^{3}$ Федотов Л.Н. Социология рекламной деятельности. М.: ОНИКС, 2007. С. 19. 